\title{
СТРАТЕГИЯ ЦИФРОВИЗАЦИИ МЕЖДУНАРОДНЫХ КОМПАНИЙ
}

\section{Е.В. Столярова*}

\begin{abstract}
Раскрыты понятие «стратегии цифровизации компании», ее ключевые отличия от ИТ-стратегии, а также стадии цифровой трансформации отрасли. Определены основные факторы, сдерживающие разработку и внедрение стратегии цифровизации в компаниях, а также ключевые факторы успеха стратегии цифровизации международных компаний. Предложены подход к разработке стратегии цифровизации компании, а также система, стимулирующая появление цифровых инноваций в компании, как часть стратегии цифровизации. Проанализирован опыт создания и внедрения стратегии цифровизации компаниями Domino's и IKEA. Сделаны выводы о необходимости такой стратегии для белорусских компаний.
\end{abstract}

Ключевые слова: международный бизнес, стратегия цифровизации, международные компании.

JEL-классификация: F23, F18.

DOI: $10.46782 / 1818-4510-2020-3-132-148$

Материал поступил 4.05.2020 2..

Развитие современного бизнеса, в том числе международного, происходит в условиях изменения поведения потребителей, которые активно в повседневной жизни используют компьютеры и смартфоны, рынков, на которых появляются новые игроки с цифровыми моделями ведения бизнеса, а также распространения цифровых технологий во всех сферах жизни общества. В такой ситуации компаниям важно адаптироваться к меняющимся условиям и осуществить цифровую трансформацию своего бизнеса. Для этого следует разработать и внедрить стратегию цифровизации компании.

Целью данной работы является изучение сути стратегии цифровизации компании, опыта международных компаний в данной области и формулировка рекомендаций для белорусского бизнеса. К задачам исследования относятся: изучение существующих научных и практических разработок в области «стратегии цифровизации» бизнеса; анализ причин и результатов цифровизации бизнеса; изучение связи стратегии цифровизации бизнеса со степенью цифровой трансформации отрасли; исследование сдерживающих факторов, а также содействующих успеху разработки и внедрения стратегии цифровизации в бизнесе; формулировка подхода к разработке стратегии цифровизации компании и системы, стимулирующей появление цифровых инноваций в компании как основы стратегии цифровизации; определение наиболее успешных цифровых компаний в мире и оценка их распределения по отраслям и странам; изучение опыта разработки и внедрения стратегии цифровизации в международных компаниях, которые являются цифровыми лидерами в сфере производства потребительских товаров; формирование верхнеуровневых рекомендаций для белорусских компаний в части стратегии цифровизации бизнеса.

Важно отметить, что на данный момент исследования в области стратегии цифровизации компаний ограничены. Основными источниками информации в этой части являются компании - лидеры в сфере стратегического консалтинга (McKinsey, BCG, Bain, Roland Berger Strategy Consultants), которые непосредственно участвуют в разработке таких стратегий для своих клиентов. Научные исследования стратегии циф-

* Столярова Екатерина Вячеславовна (e.staliarova@gmail.com), кандидат экономических наук, Белорусский государственный университет (г. Минск, Беларусь). 
ровизации компании связаны с изучением ее основных элементов и связи с корпоративной стратегией (Bharadwaj, El Sawy, Pavlou, Venkatraman, 2013), а также ее связи с ИТ-стратегией (Chan, Reich, 2007). Отдельно можно выделить исследования в области цифровизации белорусской экономики как на государственном, так и на корпоративном уровне (Ковалев, Головенчик, 2018; Давыденко, Ботеновская, Жуковская, Столярова, Руденков, Матюшевский, 2019).

По мнению ученых, понятие «стратегия цифровизации компании» напрямую связано с понятием «ИТ-стратегия». В своем исследовании А. Бжараджай, О. Сави, П. Павлов, Н. Венкатраман (Bharadwaj, El Sawy, Pavlou, Venkatraman, 2013) отмечают, что на протяжении нескольких десятков лет в научной и бизнес-литературе понятие «ИТ-стратегия» использовалось для обозначения одной из функциональных стратегий компании, задачей которой была автоматизация процессов и повышение эффективности бизнеса. При этом считалось, что ИТ-стратегия является частью корпоративной стратегии, которая определяет ее суть (Там же). Но, по мнению данных ученых, пришло время переосмыслить понятие «ИТ-стратегия». В результате увеличения роли цифровых технологий и систем стало понятно, что их использование не просто зависит от стратегии компании, они сами по себе начинают влиять на корпоративную стратегию компании, так как меняют процессы компании, изменяют требования к продуктам и услугам, размывают границы между отраслями. Появление цифровых технологий позволило многим стартапам и существующим бизнесам расширить границы своей деятельности, снизить издержки и пересмотреть свои конкурентные преимущества (Там же.). В результате они предлагают трактовать ИТ-стратегию не просто как функциональную стратегию, зависящую от бизнес-стратегии компании, а как полноценный элемент, который в сочетании с бизнес-стратегией формирует стратегию цифровизации компании (англ. digital strategy) (Там же).

А. Бжараджай, О. Сави, П. Павлов, Н. Венкатраман считают, что стратегия цифровизации компании - это стратегия компании, которая разрабатывается с учетом и ре- ализуется с использованием различных цифровых ресурсов с целью создать дополнительную ценность как для клиентов, так и для бизнеса. По их мнению, данное определение позволяет: во-первых, четко обозначить, что цифровые технологии сегодня присутствуют в компании далеко за пределами ИТ-функции, например в производстве, закупках, цепочке поставок, маркетинге; во-вторых, относиться к цифровым технологиям и системам как к «цифровым ресурсам», наличие которых является ключевым фактором успеха компании; в-третьих, рассмотреть «цифровые ресурсы» не просто как ресурсы, повышающие эффективность бизнеса, как это было в случае с ИТ-стратегией, а как ресурсы, создающие конкурентное преимущество компании (Там же.).

В консалтинговой компании BCG «стратегию цифровизации бизнеса» сравнивают с традиционной стратегией, которая по сути означает принятие грамотных инвестиционных решений для максимизации конкурентных преимуществ компании, eе роста, прибыли и ценности (Wald, de Laubier, Charanya, 2019).

В целях данного исследования автор предлагает определять стратегию цифровизации компании как долгосрочный план действий, позволяющий компании достичь стратегических целей, основываясь на использовании различных цифровых ресурсов в разных сферах своей деятельности. К таким цифровым ресурсам могут относиться разработки, основанные на использовании в том числе искусственного интеллекта, больших данных, дополненной и виртуальной реальности, интернета вещей.

\section{Цифровизащия бизнеса: причины и результать}

Говоря про цифровизацию бизнеса, важно понимать ее отличия от компьютеризации и автоматизации бизнеса. Компьютеризация - это процесс оборудования рабочих мест сотрудников компании компьютерами и/или другими гаджетами (например, планшетами). Автоматизация - это процесс уменьшения доли ручного труда при выполнении бизнес-процессов за счет использования различных устройств и программного обеспечения. Данные понятия 
имеют отношение к операционному уровню управления компаниями. Цифровизация бизнеса - это более широкое понятие, которое носит стратегический характер. Под цифровизацией бизнеса понимается всеобъемлющее изменение бизнеса (например, его бизнес-модели, бизнес-процессов, продуктов, способов продвижения) за счет использования цифровых технологий. Под цифровыми технологиями, в свою очередь, понимаются технологии, которые при передаче, обработке и хранении информации позволяют использовать вместо непрерывных сигналов дискретные сигналы, которые в большинстве случаев имеют два значения (0 и 1). Такие технологии позволяют обеспечить более высокую точность передаваемого сигнала, повысить скорость передачи информации. Среди наиболее обсуждаемых технологий на данный момент можно выделить технологии блокчейн, больших данных, интернета вещей, искусственного интеллекта, дополненной реальности (Давыденко, Ботеновская, Жуковская, Столярова, Руденков, Матюшевский, 2019).

Почему возникает потребность в стратегии цифровизации компании? Для этого есть несколько причин:

- меняются потребители компаний и их поведение. Сегодня всевозрастающее значение для бизнеса имеют представители поколения Z, которые являются активными пользователями цифровых технологий;

- уменьшается стоимость ИТ-решений и скорость их внедрения (на рынке на данный момент существует много коробочных стандартных продуктов, удобных для пользователей, которые в том числе могут быть адаптированы под потребности отдельных компаний);

- стираются границы между отраслями и снижаются барьеры для входа в отрасли технологии позволяют компаниям из традиционных отраслей выходить в несвойственные для них сферы (например, банковские игроки могут предлагать услуги в сфере телемедицины, как это делает Сбербанк);

- появляются новые игроки, деятельность которых построена исключительно на цифровых бизнес-моделях (например, AirBnb, Uber), - они могут быстро масшта- бироваться благодаря использованию цифровых технологий, а также оказывать те же услуги или производить товары с более низкими издержками, чем существующие игроки, что позволяет им быстро расширять свою клиентскую базу.

Наличие стратегии цифровизации бизнеса в современных условиях важно, так как компании могут получать следующие результаты:

- увеличить продажи за счет новых клиентов, ориентированных на покупки в интернете, и сохранения уже существующих клиентов. Это все возможно благодаря формированию для них новых предложений, позволяющих экономить время и деньги, а также более качественной поддержке клиентов и более быстрому выводу на рынок новых продуктов;

- сократить затрать путем создания цифровых цепочек поставок, которые позволяют исключить определенные этапы или минимизировать издержки на их реализацию;

- увеличить стоимость бизнеса - как правило, инвесторы более высоко оценивают стоимость высокотехнологичных компаний, так как в большей степени верят в их перспективы. Фокусирование компании в своей деятельности на цифровые технологии значительно повышает шанс на рост ее стоимости в будущем.

Например, по оценкам консалтинговой компании McKinsey компании - лидеры в части цифровизации в различных сегментах производства потребительских товаров получают выигрыши, представленные на рис. 1.

Суть стратегии цифровизации компании напрямую зависит от стадии цифровой трансформации отрасли, которая, по мнению консультантов McKinsey, включает несколько этапов (рис. 2).

Говоря о цифровой трансформации отрасли, в McKinsey вводят такое понятие, как «переломный момент цифровизации» (англ. digital tipping point). Как видно из рис. 2, цифровизация любой отрасли начинается с зарождения трендов в данной области. Это могут быть попытки отдельных компаний применить опыт из других отраслей либо разговоры менеджеров компаний о необходимости цифровизации, либо 
Стратегия цифровизации международных компаний

\begin{tabular}{|c|}
\hline Выручка \\
\hline Выше на 4-5\%, чем у конкурентов в отрасли \\
\hline Рентабельность продаж \\
\hline Выше на 2-3\%, чем у конкурентов в отрасли \\
\hline \\
\hline 3атраты на маркетинг \\
\hline Сокращение на 10-20\% \\
\hline
\end{tabular}
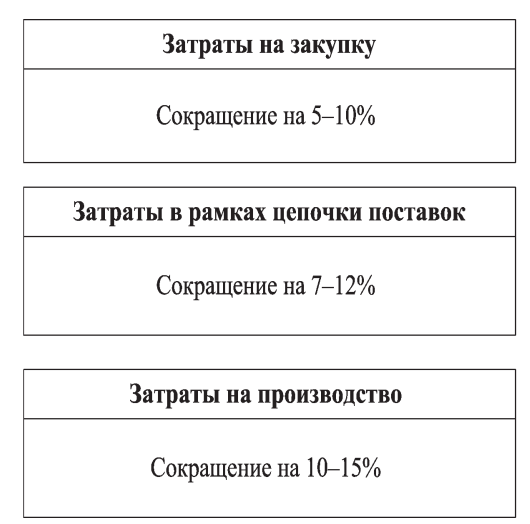

\begin{tabular}{|c|}
\hline Эффективность \\
\hline $\begin{array}{c}\text { Повышение эффективности на } 20-30 \% \\
\text { за счет автоматизации бэк-офиса }\end{array}$ \\
\hline Время обслуживания \\
\hline $\begin{array}{c}\text { Сокращение продолжительности с дней } \\
\text { до минут }\end{array}$ \\
\hline Текучесть кадров \\
\hline Сокращение текучести высококвалифицирова- \\
ных кадров на 50\%
\end{tabular}

Рис. 1. Эффекты от цифровизации бизнеса, полученные компаниями из различных сегментов производства потребительских товаров

Источник. Infographic: Why you are overdue for a digital transformation. 2018. McKinsey. URL: https:// www.mckinsey.com/industries/consumer-packaged-goods/our-insights/digital-and-analytics-in-consumer/infographic-whyyou-are-overdue-for-a-digital-transformation

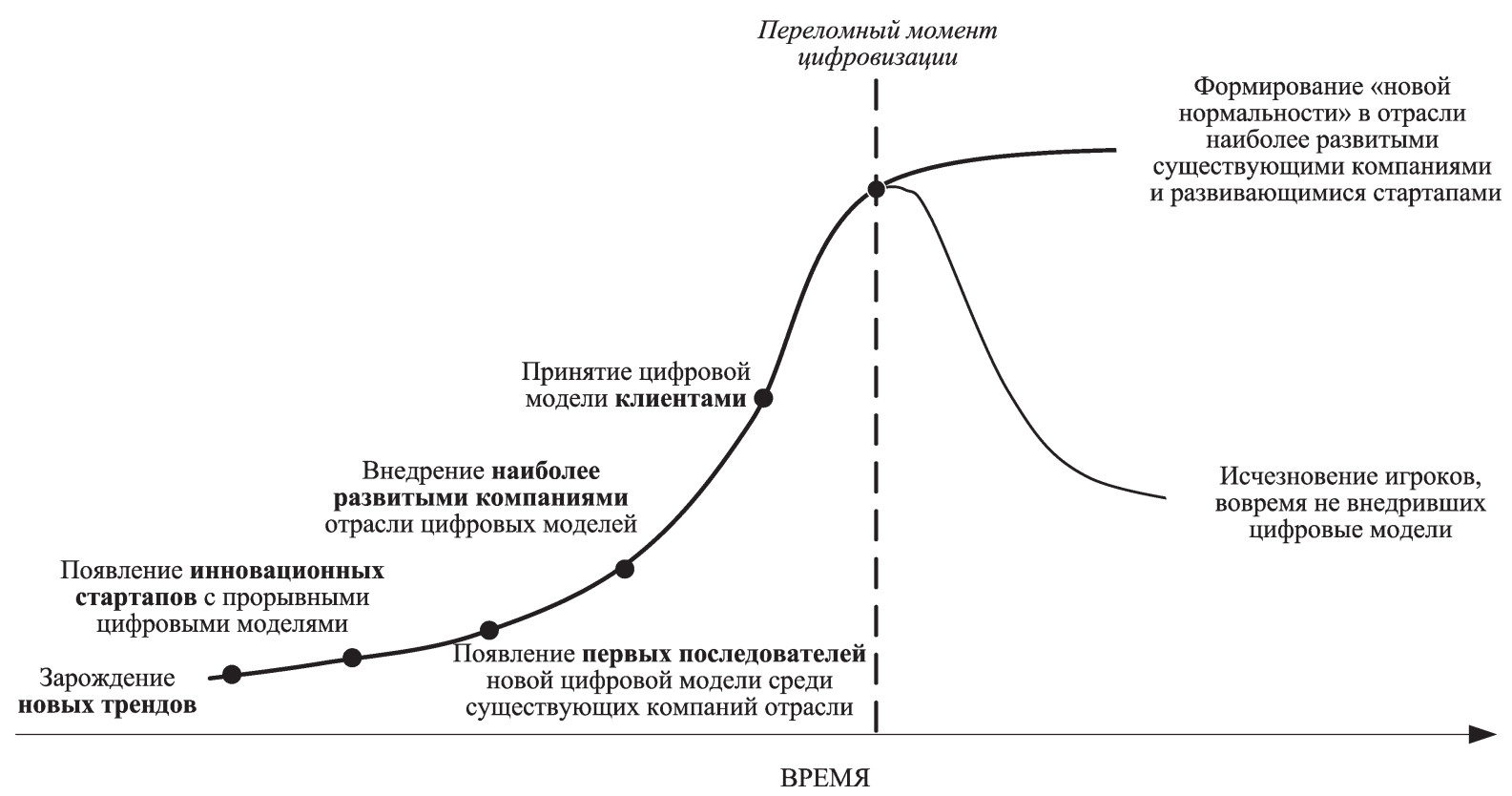

Рис. 2. Цикл цифровой трансформации отрасли

Источник. Infographic: Why you are overdue for a digital transformation. 2018. McKinsey. URL: https:// www.mckinsey.com/industries/consumer-packaged-goods/our-insights/digital-and-analytics-in-consumer/infographicwhy-you-are-overdue-for-a-digital-transformation

определенные ожидания клиентов. В результате появляются инновационные старmanь, которые предлагают инновационные цифровые модели бизнеса. Они, как правило, являются лидерами цифровизации отрасли. Постепенно наработки этих стартапов начинают внедрять первые последователи (уже существующие игроки, которые наиболее открыты к инновациям). Чтобы не навредить своему бизнесу, они могут делать это путем запуска отдельного бизнеса, основанного на использовании цифровой бизнес-модели. За ними следуют другие наиболее развитые компании отрасли, которые также внедряют цифровые модели бизнеса, после чего ключевые клиенты одобряют и принимают эту модель как новый стандарт в отрасли. Далее наступает переломный момент цифровизации. Часть игроков, которые вовремя не предприняли соответствующие шаги, вынуждены уйти с рынка либо пересматривать свою 
бизнес-модель и значительно инвестировать в ее развитие, чтобы продолжить существование, что не всегда заканчивается успехом. В конечном итоге остаются только те, кто смог уловить тренды и своевременно отреагировать на их появление ${ }^{1}$. Учитывая значимость цифровизации бизнеса, компаниям важно понять, когда нужно начать предпринимать активные шаги в этой области и как не пропустить тот момент, когда любые действия могут быть бесполезными.

Представители компании McKinsey также количественно оценили, когда наступает «переломный момент цифровизации» (рис. 3). Как видим, на ранних стадиях цифровой трансформации отрасли, когда ее уровень составляет менее $30 \%$ (т. е. меньше $30 \%$ выручки отрасли создается цифровым бизнесом), менее $10 \%$ существующих игроков в отрасли использует наступательную стратегию в области цифровизации. Но когда уровень цифровизации в отрасли приближается к 40\%, окружающая среда меняется коренным образом и наступает «переломный момент цифровизации». Это ситуация, когда игроки с

${ }^{1}$ Ungerman K., Sivaeva T., Levin R., Chen T. 2018. Infographic: Why you are overdue for a digital transformation. McKinsey. URL: https://www.mckinsey.com/industries/ consumer-packaged-goods/our-insights/digital-and-analyticsin-consumer/infographic-why-you-are-overdue-for-a-digitaltransformation цифровыми моделями бизнеса будут иметь 15\%-ю долю рынка. В этот момент существующие игроки осознают, что новые компании обладают достаточной силой, чтобы рынок пошел по другому пути развития. Бизнес сталкивается с большими рисками, если не предпринимает в такой ситуации никаких действий. Далее начинается более жесткая борьба. С одной стороны, новые игроки вынуждены сокращать свою выручку, для продолжения борьбы им нужны значительные инвестиции, сопоставимые с теми, которые делают крупные существующие игроки, чтобы догнать новичков. С другой стороны, давно существующие на рынке компании вынуждены принимать смелые решения об изменении своей бизнес-модели. В этом случае они имеют шанс остаться в игре ${ }^{3}$.

Разные отрасли могут находиться на различных стадиях своей цифровизации. Как правило, наибольшая степень цифровизации отрасли наблюдается в тех отраслях, которые ближе всего к потребителю. Примером может быть телекоммуникационная сфера. Исследование McKinsey показывает, что такие отрасли, как медиа, телеком, уже прошли от-

${ }^{2}$ Bughin J., LaBerge L., van Zeebroeck N. 2017. When to shift your digital strategy into a higher gear. McKinsey quarterly. URL: https://www.mckinsey.com/business-functions/ mckinsey-digital/our-insights/when-to-shift-your-digitalstrategy-into-a-higher-gear\#

${ }_{3}$ Там же.
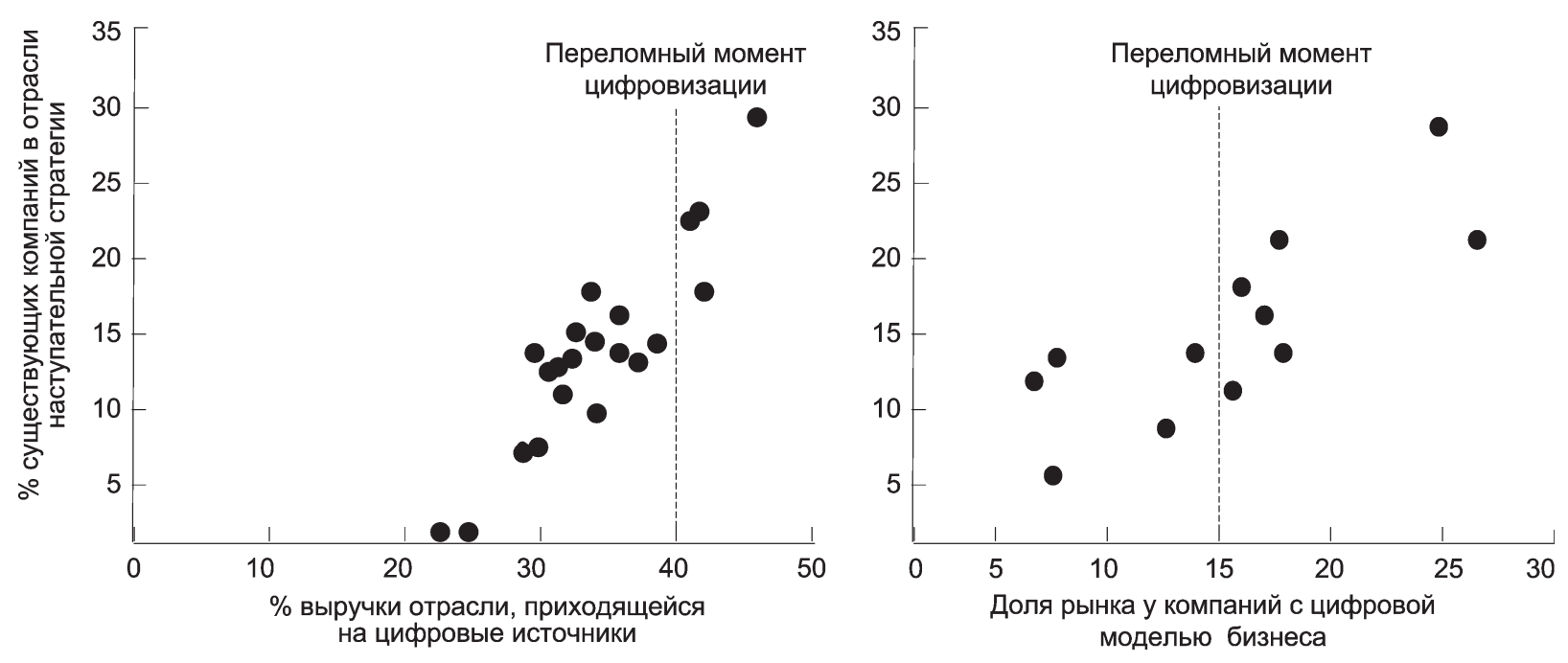

Рис. 3. Количественные показатели переломного момента в цифровизации отрасли

Источник: When to shift your digital strategy into a higher gear. 2017. McKinsey quarterly. URL: https:// www.mckinsey.com/business-functions/mckinsey-digital/our-insights/when-to-shift-your-digital-strategy-into-a-higher-gear\# 
метку в 40\% и каждый пятый существующий игрок активно реагирует на изменения. Розничный бизнес близок к переломному моменту, равному 40\%, но при этом существующие игроки менее активны ${ }^{4}$.

Ключевым для развития компаний в условиях цифровой трансформации отрасли является наличие стратегии цифровизации бизнеса. В сочетании с ресурсами, которые есть у компании, это позволит ей остаться на рынке и развиваться дальше.

Но при этом стоит признать, что у части компаний стратегия цифровизации бизнеса отсутствует либо затрагивает только отдельные блоки. Многие компании подходят к цифровизации несистемно, реализуя отдельные цифровые проекты. В результате происходит «лоскутная цифровизация», размытая во времени. Подтверждением являются данные исследования Progress, в рамках которого в 2016 г. проводился опрос 700 сотрудников различных компаний, ответственных за внедрение цифровых инициатив: $75 \%$ из них говорили, что реализуют только отдельные шаги в части цифровизации, вместо полноценной стратегии цифровизации бизнеса, даже несмотря на ее наличие; 24\% опрошенных утверждали, что компании не имеют стратегии цифровизации, хотя половина из них уже на тот момент задумывалась о ее разработке ${ }^{5}$; 96\% тех, у кого не было стратегии, считали важным процесс цифровой трансформации, хотя 48\% отмечали, что это не основной приоритет. Большая часть опрошенных также признавала, что их коллеги ошибочно думают, что они уже внедряют стратегию цифровизации бизнеса. 55\% респондентов оценивали, что у них есть год или даже меньше, перед тем как их компании начнут нести убытки в случае бездействия в области цифровизации, $59 \%$ считали, что уже может быть слишком поздно.

Такое состояние дел можно объяснить несколькими причинами:

- недостаточный уровень грамотности в области цифровизации. У части руководителей, в принципе, нет понимания, что

${ }^{4}$ Там же.

${ }^{5}$ McKendrick J. 2016. What, exactly, is a digital strategy? It depends upon who you ask. Forbes. URL: https:// www.forbes.com/sites/joemckendrick/2016/06/04/what-exactlyis-a-digital-strategy-it-depends-upon-who-you-ask/\#44dcd23a7e81 такое цифровизация и какую ценность она создает, а это ведет к их нежеланию даже разбираться в таких «сложных» вопросах. Часть путает цифровизацию с компьютеризацией и автоматизацией либо ассоциирует цифровизацию с наличием сайта, автоматизацией бухгалтерского учета, либо ведением социальных сетей;

- для многих представителей бизнеса стратегия цифровизации бизнеса часто равняется стратегии цифрового маркетинга, а это означает в их понимании, что по сути они все делают - ведут социальные сети, используют контекстную рекламу, анализируют google-аналитику;

- даже при наличии понимания важности стратегии цифровизации бизнеса руководители не до конца понимают, как разработать такую стратегию, из чего она должна состоять. Усложняется все тем, что у каждого подразделения в компании есть свое понимание цифровизации и ее эффектов;

- излишняя уверенность в существующем бизнесе, особенно в случае наличия высокой маржи у компании и успешного ведения бизнеса на протяжении последнего времени. Часть руководителей верит в долгосрочную устойчивость своего бизнеса. Они считают, что у них есть хорошая позиция на рынке, лояльные клиенты, данные об этих клиентах, следовательно, им ничего не угрожает. Другая часть, понимая важность цифровизации бизнеса, боится путем цифровизации навредить существующего успешному бизнесу. Это дилемма новатора, которую описывал Клейтон Кристонсон (Wald, de Laubier, Charanya, 2019);

- недоцценка последствий прихода на рынок конкурентов с цифровой бизнес-моделью или отсутствия понимания изменений в условиях конкуренции в принципе;

- недостаточный уровень амбициозности компаний и их собственников;

- отсутствие реальных угроз на рынке. Иногда компания действительно является лидером, в отрасли нет «цифровых» конкурентов, поэтому в конкретный момент времени нет необходимости что-либо менять. Но эта стратегия может быть успешной только в краткосрочной или среднесрочной перспективе. Учитывая развитие цифрового бизнеca, такие конкуренты появятся во всех от- 
раслях. По мнению CEO компании Netflix, «компании редко умирают из-за того, что двигаются слишком быстро, они чаще погибают из-за того, что двигаются слишком медленно» (Wald, de Laubier, Charanya, 2019);

- при четком понимании сути и важности стратегии цифровизации в компании могут отсутствовать ресурсы для ее разработки и/или внедрения.

К сожалению, нужно признать, что не все разработанные и внедряемые стратегии цифровизации являются успешными. Подтверждением этому может быть исследование компании Accenture. Было опрошено 1350 руководителей из различных отраслей бизнеса, которые заявили, что в период с 2016 по 2018 г. совместно потратили чуть более 100 млрд долл. США на масштабирование цифровых инноваций; 78\% из опрошенных считают, что не получили ожидаемого результата от цифровизации бизнеса $^{6}$. Среди тех, кому реализация стратегии цифровизации бизнеса не принесла ожидаемых результатов, можно увидеть и имена больших транснациональных компаний, например General Electric.

Здесь важно понимать ключевые факторы успеха разработки и реализации стратегии цифровизации бизнеса, к которым можно отнести:

- наличие осознания руководством компании того, что ей нужна стратегия цифровизации бизнеса;

- четкое понимание у руководства и всех сотрудников, зачем нужна стратегия цифровизации бизнеса и как она будет интегрирована в традиционный бизнес;

- «нестандарный» взгляд на развитие отрасли и своей позиции в ней при разработке стратегии цифровизации. Например, в современных условиях важно думать в категориях не просто отдельно взятого бизнеса, а целой цифровой бизнес-системы и партнерств с различными игроками рынка, в том числе за пределами конкретной отрасли;

- четкое понимание рисков стратегии цифровизации бизнеса и необходимых инвестиций, в том числе их источников;

${ }^{6}$ Coke R. 2020. 3 multi-billion pound companies doing digital transformation right. CEOToday. URL: https:/ www.ceotodaymagazine.com/2020/03/3-multi-billion-poundcompanies-doing-digital-transformation-right/
- скорость и смелость - особенно это важно для традиционных, устоявшихся бизнесов, которые боятся сложностей для себя;

- наличие специалистов, способных создать такую стратегию и обеспечить ее внедрение - ее разработка может быть передана на аутсорсинг консалтинговым компаниям в области стратегического менеджмента;

- необходимость разработки технологической платформы, способной интегрировать в бизнес-экосистему различных игроков.

\section{Этапы разработки стратегии иифровизации компании}

Разработка стратегии цифровизации компании, по мнению автора статьи, должна включать несколько ключевых этапов, представленных на рис. 4.

1) Определение амбиций компаний $и$ собственников бизнеса

Амбиции компании и ее собственников в части цифровизации бизнеса являются отправным пунктом в части разработки стратегии цифровизации. Они являются базовыми для дальнейшего определения целей и направлений цифровизации бизнеса.

2) Анализ рынка

Данная стадия предполагает, что компания изучает динамику рынка, потенциал его роста, оценивает факторы, которые будут влиять на его развитие, в том числе поведение потребителей, а также очень пристально изучает уровень текущей и потенциальной конкуренции. В части анализа конкурентов особенно важно идентифицировать игроков с новыми цифровыми бизнес-моделями, включая тех, которые только их тестируют, оценить потенциал и скорость их роста. Также дополнительно важно посмотреть на цифровые бизнес-модели в других отраслях, чтобы понять, насколько легко они могут быть внедрены в конкретной отрасли или даже компании. Это поможет понять в том числе, в каком направлении рынок будет развиваться дальше.

3) Анализ существующих компетениий компании и готовность к цифровой трансформаиии

На данном этапе важно проанализировать степень готовности компании к цифровизации. А именно, есть ли соответствующие трудовые и финансовые ресурсы, насколько 
Стратегия цифровизации международных компаний

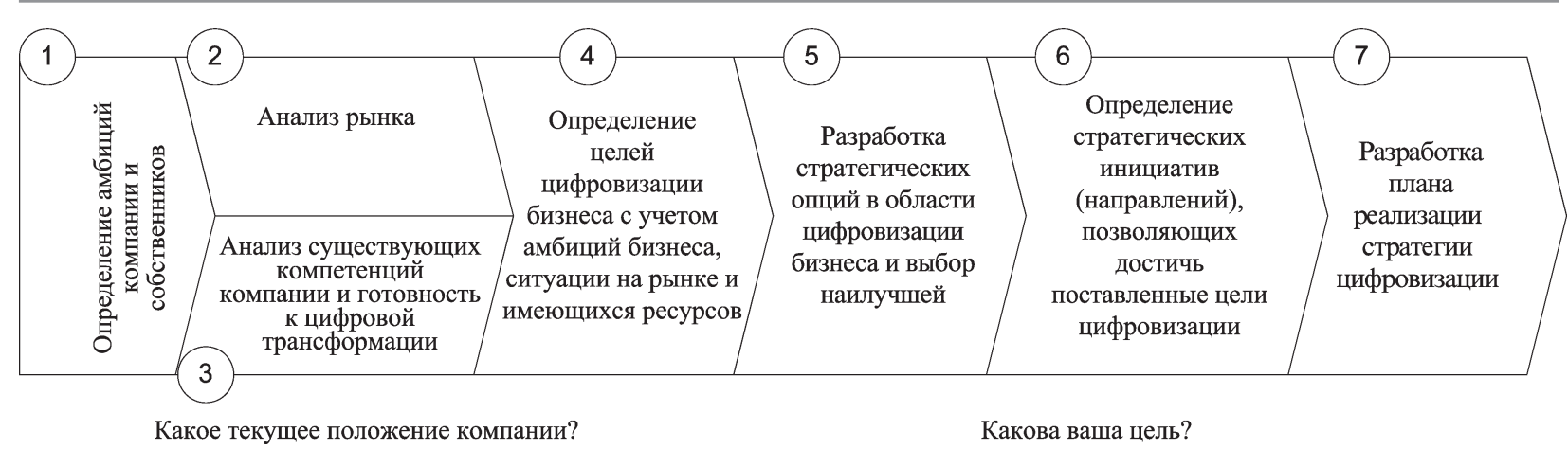

Рис. 4. Этапы разработки стратегии цифровизации бизнеса

Источник. Авторская разработка по: The five rules of digital strategy. BCG. 2019. URL: https://www.bcg.com/ publications/2019/five-rules-digital-strategy.aspx

компания в принципе готова к изменениям, есть ли потенциально команда, которая может впоследствии стимулировать процесс внедрения стратегии цифровизации.

4) Определение целей цифровизации бизнеса с учетом амбииий бизнеса, ситуации на рынке и имеющихся ресурсов

Цель цифровизации бизнеса должна быть результатом сочетания амбиций собственника бизнеса, текущей ситуации на рынке, а также ресурсов и компетенций компании. Очень важно, чтобы компания понимала, зачем в целом необходимо осуществлять цифровизацию и какого глобального результата необходимо достичь. Оценка этого глобального результата может быть выражена как в качественном, так и количественном виде. Например, для российской компании Сбербанк стратегия цифровизации по сути является частью ее корпоративной стратегии. В рамках стратегии до 2020 г. компания четко заявила не просто об укреплении своих позиций в финансовой сфере, а о своем превращении в высокотехнологичную компанию и желании конкурировать с самыми известными высокотехнологичными компаниями мира, например Facebook, Amazon, Apple. Компания Renault, в свою очередь, ожидает от стратегии цифровизации 25\%-й прирост операционной прибыли (Wald, de Laubier, Charanya, 2019). При этом важно, чтобы цель цифровизации была увязана с общей целью развития бизнеса.

В рамках данной стадии важно ответить на вопрос, в какой отрасли компания видит свое будущее развитие. На современном этапе развития международного бизнеса благо- даря использованию цифровых технологий происходит размытие границ между отраслями. Таким образом формируются целые бизнес-экосистемы, которые уже сегодня называют «цифровыми экосистемами». В этой связи важно определить, планирует ли компания создавать такую экосистему, стать частью чьей-то экосистемы или остаться в стороне от данного тренда.

5) Разработка стратегических опщий в области цифровизащии бизнеса и выбор наилучшей

Опции развития в части цифровизации могут касаться как всего бизнеса в целом (например, компания может принять решение развивать цифровую экосистему либо специализироваться на каком-то цифровом продукте или услуге), так и отдельных направлений (цифровизации самих продуктов, цифровизации цепочки поставок, цифровизации продаж или маркетинга). Здесь важно понимать, что степень вклада цифровизации зависит от специфики отрасли и ее отдельной функции. Например, если речь идет о потребительских товарах, то наибольший вклад принесут цифровой маркетинг и цифровые каналы продаж. На данном этапе важно оценить финансовый эффект от каждой из рассматриваемых стратегических опций в части цифровизации, от клиентов до партнеров, и выбрать наиболее подходящий вариант для реализации.

6) Определение стратегических иничиатив (направлений), позволяющих достичь поставленные цели цифровизации

Выбрав определенную стратегическую опцию для цифровизации, следует определить набор стратегических инициатив (очень 
конкретных направлений действий) для реализации. Выбор таких инициатив должен быть основан на оценке ценности, которые они создают для бизнеса и клиентов.

Для всех проработанных инициатив важно просчитать эффект и оценить степень риска, связанного с их реализацией. Эти риски целесообразно сравнивать с ожидаемым результатом. При определении стратегических инициатив важно очень четко разделить все инициативы на две категории: те, которые могут быть быстро внедрены с минимальными затратами, а также те, которые требуют большей проработки и больше ресурсов. Инициативы, обеспечивающие быстрый результат, следует внедрять максимально быстро, чтобы, с одной стороны, показать ценность цифровизации как таковой, а с другой стороны, чтобы получить экономию ресурсов или дополнительную выручку, которые можно будет использовать для более масштабной цифровизации. Также необходимо выбрать оптимальное количество легко управляемых инициатив, приносящих наибольшую ценность. При этом важно, чтобы новые инициативы были гармонично связаны с существующим бизнесом и создавали дополнительный эффект.

Внедрение стратегии цифровизации может потребовать изменения организационной структуры компании. В этой ситуации важно, чтобы существующая или новая структура обеспечивала компании гибкость. Так как в условиях изменений, в том числе цифровизации, выживает тот, кто в наибольшей степени готов адаптироваться к новым условиям и готов меняться. И это не обязательно самый сильный игрок. В случае устоявшегося бизнеса, возможно, стоит создать отдельный цифровой бизнес, который не будет привязан к существующего бизнесу и будет развиваться как самостоятельное направление.

Примером может быть компания Unilever. Одной из инициатив в рамках цифровизации бизнеса было создание цифровых хабов в 24 странах к 2020 г. Это связано с тем, что компания объявила данные важным активом для бизнеса. Ежедневно она получает 1,5 терабайт данных из 150 источников информации (Wald, de Laubier, Charanya, 2019).
7) Разработка плана реализации стратегии цифровизации

План реализации стратегии цифровизации должен включать конкретный перечень задач, ответственных и сроки реализации. Учитывая важность процессов цифровизации, необходимо определить, кто должен возглавлять разработку и внедрение стратегии цифровизации бизнеса. В целом, как уже было сказано выше, важно, чтобы инициатива о данной стратегии исходила от руководителя компании, ведь такое решение влияет на весь бизнес. Это также является гарантией того, что внедрению инициатив будет уделено пристальное внимание. Но учитывая большое количество задач у руководителя в принципе, важно, чтобы непосредственной реализацией стратегии цифровизации в компании занимался отдельный человек. Его позиция, как правило, называется CDO (Chief Digital Officer), этот человек является ответственным за цифровую трансформацию бизнеса. Его основные задачи - разработка стратегии цифровизации бизнеса, определение четких планов внедрения цифровой стратегии, их мониторинг, обсуждение проблем с целью своевременной корректировки. Иногда изменяющиеся условия могут потребовать пересмотра самой стратегии, набора инициатив или конкретных действий для их реализации. Очень важно, чтобы у этого человека было достаточно влияния в компании, поскольку в процесс цифровизации вовлечены различные подразделения, каждый со своим отношением к цифровизации бизнеса, не всегда положительным. Как правило, в международных компаниях на должность CDO принимают специалистов с опытом работы в высокотехнологичных компаниях (например, Google, Facebook). Примером может быть CDO компании IKEA, который до прихода в компанию на эту позицию занимал ответственные должности в таких компаниях, как Google и Samsung.

Важно понимать отличия должности CDO от должности CTO (Chief Technology Officer) или CIO (Chief Information Officer). СТО - это человек, ответственный за выбор и правильное внедрение в компании различных технологий, разработку или внедрение различных продуктов, основанных на технологиях. СІО - человек, который отвечает за 
информационную среду компании и ее основные элементы, например серверы, телекоммуникационную инфраструктуру, центры обработки данных. Задача CDO - задать направления для цифровизации бизнеса и мониторить реализацию мероприятий по этим направлениям. В рамках данного процесса ему потребуются компетенции как СТО, так и CIO. В этом смысле должность CDO имеет более стратегический характер.

В целом для реализации стратегии цифровизации важна сплоченная проектная команда, обладающая необходимыми компетенциями, поддерживающая и верящая в цели компании. В случае отсутствия компетенций важно привлечь соответствующих людей или инвестировать в развитие определенных компетенций у сотрудников компании. Важно, чтобы команда была замотивирована и находилась в постоянном процессе развития.

Для внедрения цифровых инициатив необходимы изменения в корпоративной культуре компании. Фокус корпоративной культуры на цифровизацию позволяет привлекать людей, которые будут продвигать идею цифровизации. Как правило, лучше всего с этим справляются представители поколения Z, которым знакомы цифровые новшества.

Цифровизация любого бизнеса невозможна без доступа к цифровым инноваци- ям. Учитывая высокую скорость появления и проникновения инноваций в бизнес, каждая отдельная компания не способна создавать эти инновации исключительно внутри компании. Именно поэтому любому бизнесу важно создать систему, стимулирующую появление цифровых инноваций в компании (рис. 5). Под такой системой автор предлагает понимать набор взаимосвязанных элементов в деятельности компании, которые стимулируют появление и развитие цифровых инноваций в компании.

Одним из ключевых элементов такой системы является комплекс инструментов, стимулирующих появление цифровых инноваций в компании. К таким инструментам автор предлагает относить в том числе деятельность внутренних исследовательских подразделений компании, гранты и конкурсы от компаний для владельцев потенциально интересных идей, создание компанией совместных лабораторий с университетами, корпоративных инкубаторов, акселераторов, технопарков, а также создание корпоративных венчурных фондов, осуществление сделок по слиянию и поглощению.

Также важным элементом в этой системе являются источники финансирования цифровых инноваций. В случае неэффективной прежней деятельности это может быть серьезным вопросом. Одним из способов финансирования цифровых иннова-

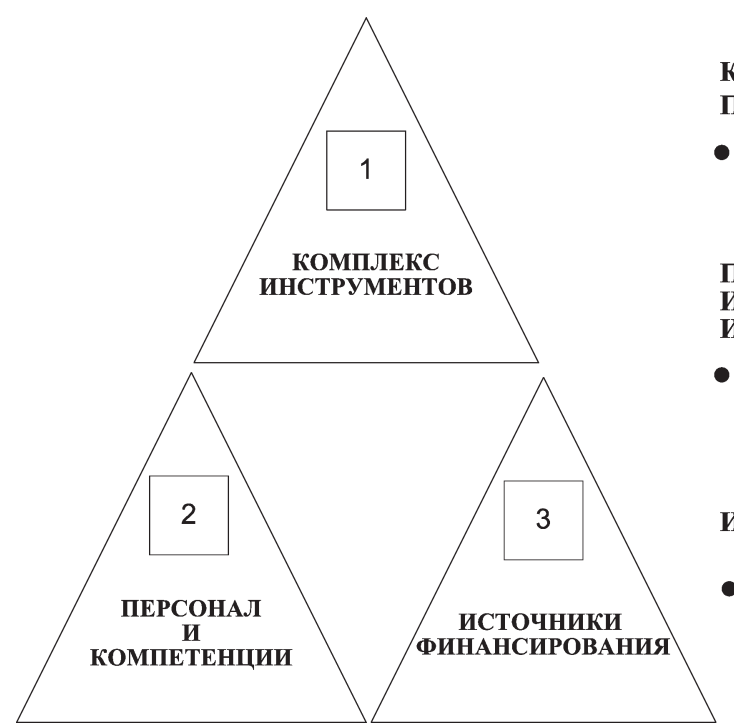

\section{КОМПЛЕКС ИНСТРУМЕНТОВ, СТИМУЛИРУЮЩИХ ПОЯВЛЕНИЕ ЦИФРОВЫХ ИННОВАЦИЙ В КОМПАНИИ}

- Создание и использование комплекса инструментов для стимулирования инноваций - от грантов и конкурсов до деятельности корпоративных венчурных фондов и сделок по слиянию и поглощению

\section{ПЕРСОНАЛ И КОМПЕТЕНЩИИ ДЛЯ СОЗДАНИЯ ИЛИ СТИМУЛИРОВАНИЯ ПОЯВЛЕНИЯ ЦИФРОВЫХ ИННОВАЦИЙ В КОМПАНИИ}

- Формирование команды, цель которой поиск таких инноваций и их внедрение в компании - иногда требуется формирование или усиление компетенций сотрудников в части создания цифровых инноваций внутри компании

\section{ИСТОЧНИКИ ФИНАНСИРОВАНИЯ ЦИФРОВЫХ ИННОВАЦИЙ}

- Определение источников финансирования цифровизации бизнеса, в том числе за счет сокращения маржи бизнеса

Рис. 5. Система, стимулирующая появление цифровых инноваций в компании

Источник. Авторская разработка. 
ций является перераспределение ресурсов между нецифровыми и цифровыми направлениями бизнеса.

Важно также иметь команду, которая будет осуществлять поиск таких инноваций с использованием всех инструментов и стимулировать их внедрение в компании.

\section{Наиболее цифровые компании мира}

В целом необходимо отметить, что компании в международном бизнесе отличаются по степени своей цифровизации. По нашему мнению, компанию можно считать цифровым лидером, если значительную часть своей выручки она получает с использованием цифровых технологий, при этом такая выручка характеризуется высокими темпами прироста. Конкретные значения выручки и темпов прироста зависят от отрасли и могут меняться по мере изменения уровня цифровизации всей отрасли.

Для определения наиболее цифровых компаний мира используются различные рейтинги. Наиболее известным из них является рейтинг Top 100 Digital Companies, который составляется журналом Forbes. При его разработке анализируются публичные компании из списка крупнейших компаний мира Global 2000 в априори наиболее цифровых отраслях (технологии, медиа, цифровая розница и телекоммуникации). Компании оцениваются по таким параметрам, как выручка, прибыль, рост активов и динамика стоимости акций за год. Впер- вые список был представлен в 2018 г. ${ }^{7}$ Проведенный нами анализ полного списка этих компаний позволяет сделать вывод о том, что наибольшая часть цифровых компаний находится в США, Китае и Японии (рис. 6). Другие страны, в том числе страны с малой экономикой, представлены в этом списке большей частью всего лишь двумя или одной компанией (например, Швейцария, Финляндия, Ирландия, Норвегия, Швеция).

На рис. 7 показано распределение компаний этого же рейтинга по отраслям. Как видим, наибольшее количество компаний в этом списке относится к телекоммуникационной отрасли или производству полупроводников. Именно эти компании наиболее активно развиваются в части цифровизации.

Компании - лидеры в части цифровизации бизнеса представлены в табл. 1. Наиболее цифровые компании - это те, которые непосредственно связаны с информационными технологиями. Большая часть (8 компаний $)$ - это компании из США. Они работают в области телекоммуникаций, производства компьютерных устройств и программного обеспечения и предоставления компьютерных услуг.

Важно отметить, что в данном списке пока нет компаний из сферы производства потребительских товаров и не так значительно представлена финансовая сфера. Это

7 URL: https://www.forbes.com/sites/andreamurphy/ 2018/09/20/the-2018-digital-100/\#3469d6496137

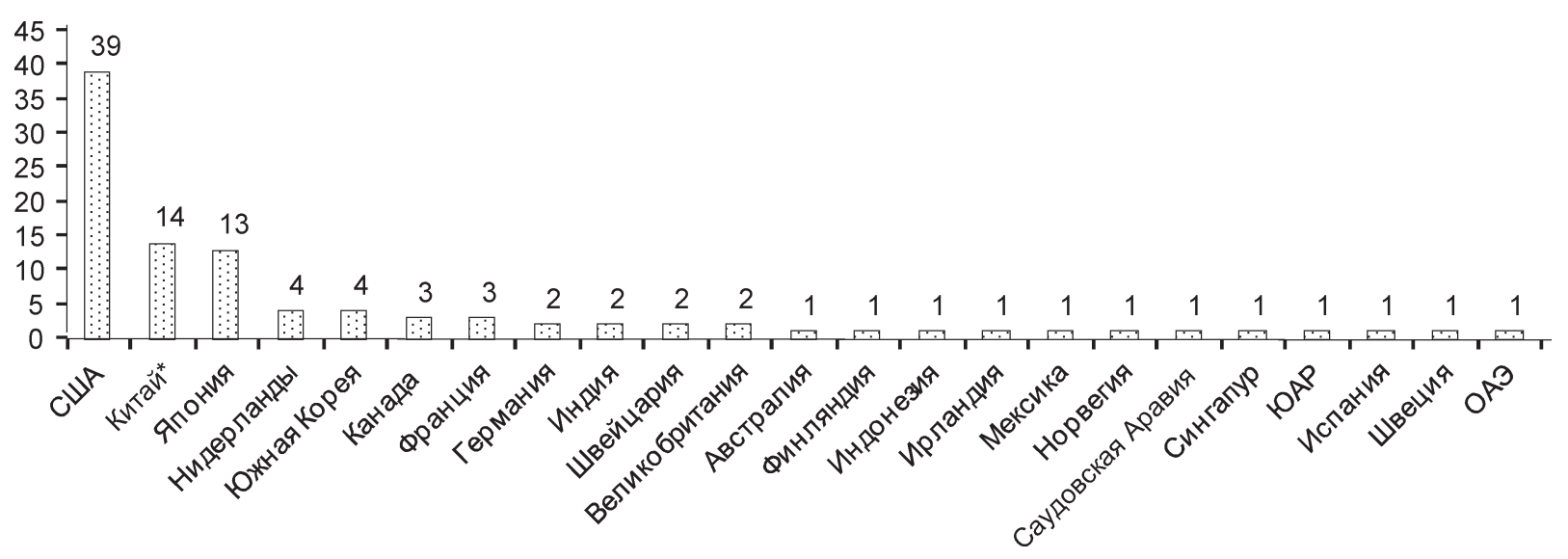

* В список китайских компаний включены 3 компании из Гонконгда и 2 из Тайваня, которые в рейтинге Top 100 Digital Companies выделены отдельно.

Рис. 6. Распределение компаний из списка Тор 100 Digital Companies по странам

Источник. URL: https://www.forbes.com/top-digital-companies/list/\#tab:rank 


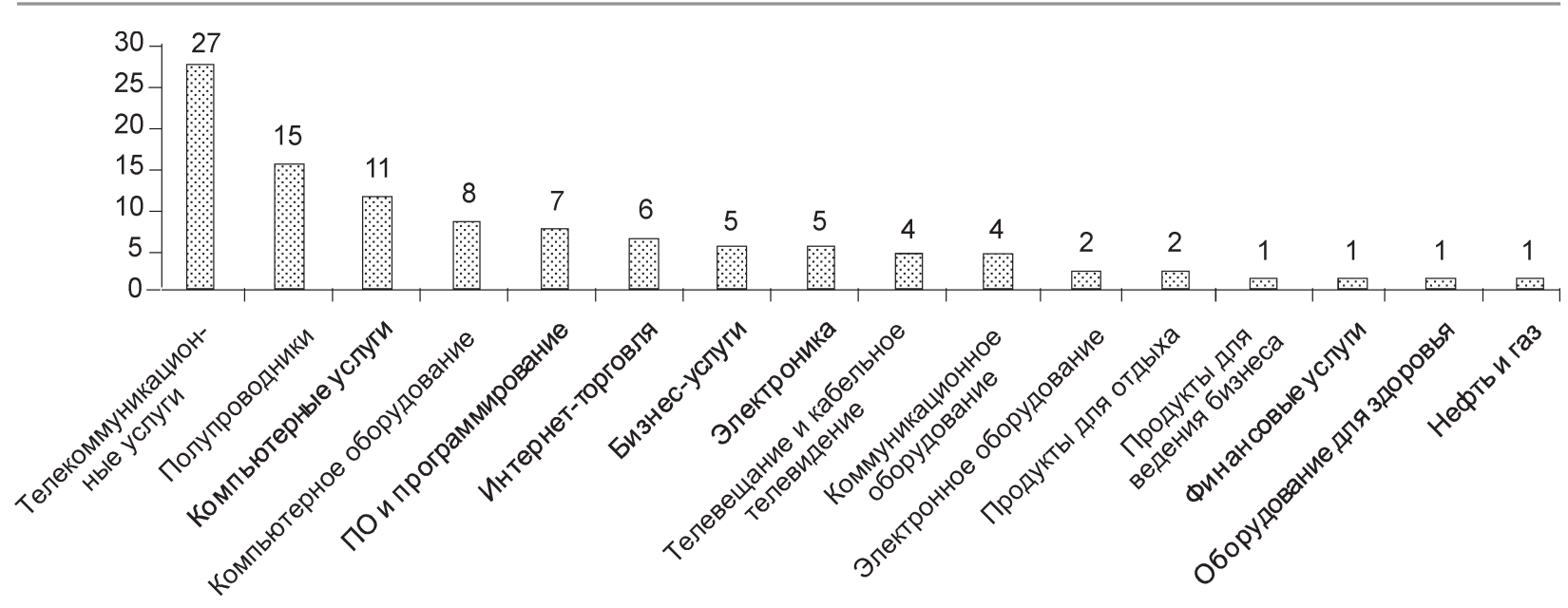

Рис. 7. Распределение компаний из списка Top 100 Digital Companies по отраслям \#tab:rank

Источник. Авторские расчеты и визуализация по: URL: https://www.forbes.com/top-digital-companies/list/

может быть связано с тем, что, несмотря на свою активную цифровизацию, компании из данных сфер все еще отстают по уровню цифровизации от игроков в указанных областях.

\section{Примеры стратегий цифровизащии международных компаний}

Среди компаний в сфере производства потребительских товаров, которые активно цифровизируются, можно назвать IKEA, Domino's, Starbucks, Nike, Unilever, McDonald's.

Рассмотрим примеры стратегии цифровизации компаний Domino's и IKEA.

Domino's является примером успешного внедрения стратегии цифровизации. Данная компания начала говорить о такой стра- тегии еще в начале 2010-х гг., хотя наиболее активно цифровизация началась в 2015-2016 гг. Основная цель всей цифровизации заключалась в изменении имиджа компании. В начале 2010-х Domino's accoциировалась с дешевой пиццей быстрого приготовления. Компания же хотела, чтобы ее продукт воспринимался как хорошая еда, создающая ценность для клиента. В результате, меняя продукт, уровень сервиса и внедряя многоканальную платформу взаимодействия с клиентом, компании удалось изменить свой имидж. Также изменились финансовые результаты. Благодаря стратегии цифровизации компания стала крупнейшей сетью пицщерий в мире, обогнав Pizza Hut. Онлайн-продажи в 2019 г.

Топ-10 компаний в списке Top 100 Digital Companies

\begin{tabular}{|c|l|l|l|}
\hline $\begin{array}{c}\text { Позиция } \\
\text { в рейтинге }\end{array}$ & \multicolumn{1}{|c|}{ Компания } & \multicolumn{1}{|c|}{ Сфера } \\
\hline 1 & Apple & Компьютерные устройства & США \\
\hline 2 & Microsoft & $\begin{array}{l}\text { Программное обеспечение } \\
\text { и программирование }\end{array}$ & США \\
\hline 3 & Samsung Electronics & Полупроводники & Южная Корея \\
\hline 4 & Alphabet & Компьютерные услуги & США \\
\hline 5 & AT\&T & Телекоммуникационные услуги & США \\
\hline 6 & Amazon & Онлайн-торговля & США \\
\hline 7 & Verizon Communications & Телекоммуникационные услуги & США \\
\hline 8 & China Mobile & Телекоммуникационные услуги & Китай (Гонконг) \\
\hline 9 & Walt Disney & Телевещание и кабельное телевидение & США \\
\hline 10 & Facebook & Компьютерные услуги & США \\
\hline
\end{tabular}

Источник. URL: https://www.forbes.com/top-digital-companies/list/\#tab:rank 
составляли большую часть продаж и росли значительно быстрее, чем общие продажи (табл. 2).

Таблица 2

Результаты общих и онлайн продаж в Domino's и IKEA

\begin{tabular}{|l|c|c|}
\hline Параметр для сравнения & Domino's & IKEA \\
\hline $\begin{array}{l}\text { Доля онлайн-продаж } \\
\text { в 2019 г.*, \% }\end{array}$ & 67 & 7 \\
\hline $\begin{array}{l}\text { Темп прироста онлайн- } \\
\text { продаж в 2019 г.*, \% }\end{array}$ & 18,2 & 49,3 \\
\hline $\begin{array}{l}\text { Темп прироста всех } \\
\text { продаж, \% }\end{array}$ & 11,9 & 6,5 \\
\hline
\end{tabular}

* Под годом понимается фискальный год каждой отдельной компании.

Источник. URL: https://static1.squarespace.com/ static/5bd052c7c46f6d 0e 23b $11 \mathrm{afb} / \mathrm{t} / 5 \mathrm{~d} 5 \mathrm{c} 7 \mathrm{~b} 89 \mathrm{c}$ 3e6df0001a41d2c/1566342143706/FY19+Appendix+ 4E++Annual+Report.pdf; https://preview.thenewsmarket. com/Previews/IKEA/DocumentAssets/551191_v2.pdf; https://preview.thenewsmarket.com/Previews/IKEA/ DocumentAssets/525222.pdf

Результатом внедрения стратегии также стал рост стоимости акций компании, который за период с 29 апреля 2015 г. по 28 апреля 2020 г. составил 2,25 раза (или рост $325 \%$ ) (рис. 8). И даже замедление экономической активности, связанное с COVID-19, только временно повлияло на акции компании в феврале 2020 г., после чего уже в апреле был достигнут прежний уровень их стоимости. Стоимость акций компании Domino's с 28 апреля 2015 г. до 28 апреля 2020 г. росла бо- лее быстрыми темпами, чем акции Google, одной из крупнейших технологических компаний (см. рис. 8).

К ключевым характеристикам стратегии цифровизации компании Domino's можно отнести:

- ясное стратегическое видение цифровизации бизнеса, которое заключалось в построении всеобъемлющей и многоканальной платформы для постоянной связи с клиентом;

- четкая связь изменений в продукте, маркетинге и обслуживании клиентов с изменениями в сфере используемых информационных систем и технологий, что в том числе было возможно благодаря эффективной коммуникации подразделений маркетинга и ИТ;

- гибкость в рамках реализации стратегии цифровизации на основе подхода agile - в компании пробовали различные элементы стратегии цифровизации, оценивая результат их внедрения и выбирая те, которые дают максимальный эффект. Идея заключалась в том, чтобы стратегия цифровизации не воспринималась как один длительный проект, а как набор маленьких быстро реализуемых шагов, позволяющих обеспечить наилучший опыт для клиентов;

- фокус на смартфоны в рамках стратегии цифровизации: заказы через смартфоны стали основным источником выручки компании. Кроме того, появилась возможность получить информацию о потребителях,

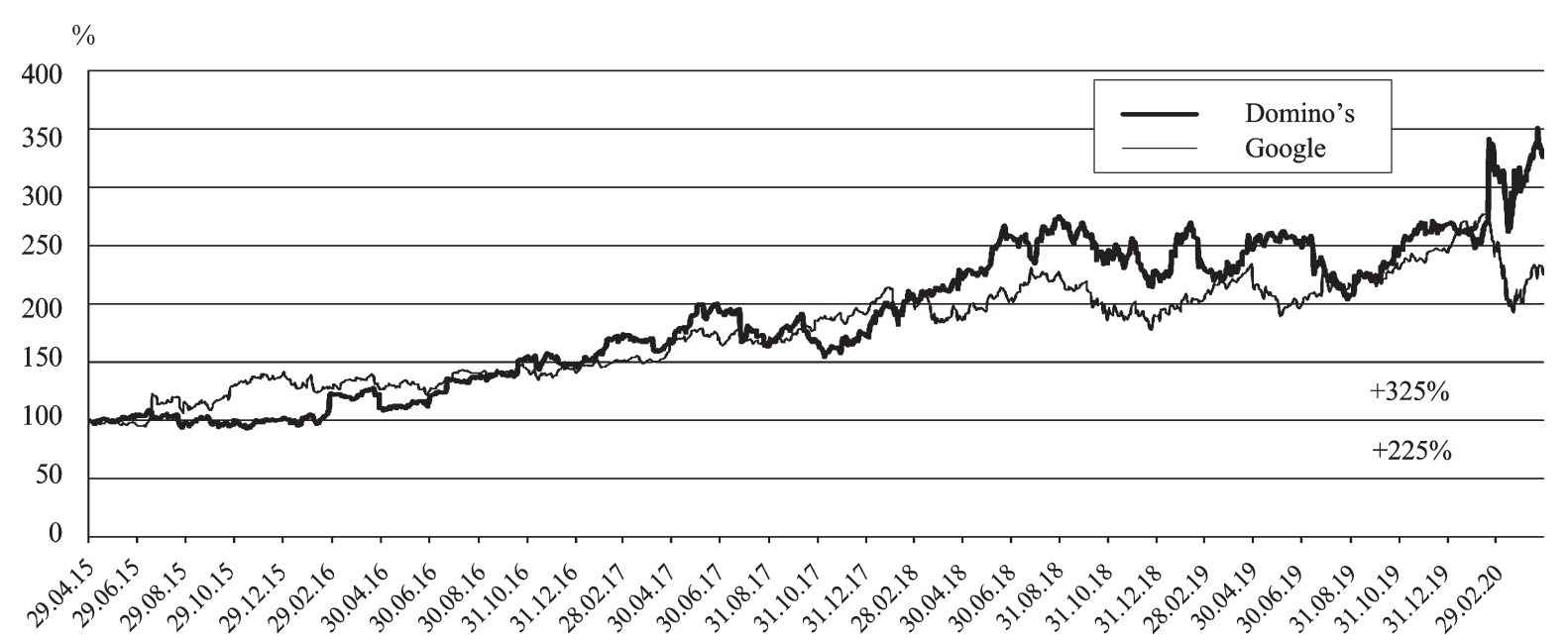

Рис. 8. Темпы роста стоимости акции (цена закрытия) по сравнению с ценой 29 апреля 2015 г., \%

Источник. Авторская разработка по: https://www.cnbc.com/quotes/?symbol=DPZ; https://www.cnbc.com/ quotes/?symbol=GOOGL\&qsearchterm=google 
чтобы сформировать персонализированное предложение;

- применение облачных технологий, что позволило расширить количество обслуживаемых клиентов (в облаке работают все системы, в том числе ERP и вся цепочка поставок);

- внедрение и развитие культуры постоянных улучшений в компании. По мнению CDO компании, «быстрое движение вперед для них означает постоянное обучение, итерации, перезапуски и тестирование. Мы должны были научиться спокойно относиться к неудачам, ведь если ты быстро развиваешься, не все будет совершенно. Следует очень хорошо понимать, как правильно тестировать различные вещи. Лучше ставить небольшие эксперименты, чтобы понять, что происходит, вместо того чтобы запускать значительные проекты и ждать результаты. Важно научиться правильно понимать данные» 8 .

${ }^{8}$ Abramovich G. 2018. Domino's CDO shares his secret sauce for innovation. CMO.by Adobe. URL: https:// cmo.adobe.com/articles/2018/4/dominos-cdo-right-internalstructure-to-be-digital-innovator.html\#gs.4mvk2p

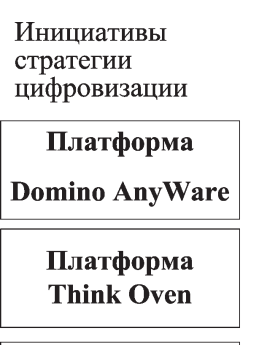

Pizza Tracker
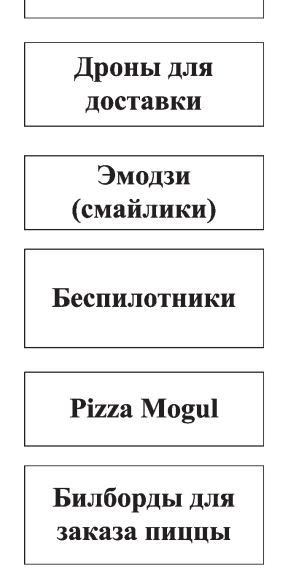

Пицца к ланчу
Описание

Отдельные инициативы в области цифровизации, которые были внедрены в Domino's, представлены на рис. 9. Создание всех приложений и платформ внутри компании осуществляется в Domino's с использованием внутренних компетенций сотрудников. Для реализации стратегии цифровизации в компании предусмотрена роль CDO. По его утверждению, «Domino's is brand in progress», что предполагает: компания никогда не закончит цифровую трансформацию и продолжит развиваться, чтобы улучшать клиентский опыт ${ }^{9}$.

IKEA. Цифровизация бизнеса IKEA стала частью большой трансформации бизнеса, которая началась в 2017 г. Основной целью такой трансформации была модернизация бизнеса IKEA с целью увеличить онлайн-продажи и улучшить клиентский опыт в магазинах - и все это с сохранением особого шарма IKEA, который создавался десятилетиями ${ }^{10}$. Одна из проблем, которую решает ком-

9 Там же.

10 URL: https://www.europeanceo.com/profiles/ thinking-outside-the-box-jesper-brodin-takesikea-digital/ 
пания путем внедрения стратегии цифровизации, - это переосмысление бизнес-модели, основанной на функционировании больших гипермаркетов IKEA, а также сокращение затрат на доставку. Ключевая задача до 2021 г. - это трансформация IKEA в многоканальный бренд, который позволяет приобретать свои товары как онлайн, так и в мини-магазинах в городе, а также в традиционных больших магазинах за городом.

На данный момент онлайн-продажи составляют около 7\% (см. табл. 2), что значительно меньше, чем у компании Domino's. Но это значительный прогресс с момента запуска масштабной цифровизации в 2018 г. Компания IKEA не является публичной, поэтому невозможно оценить влияние ее стратегии цифровизации на стоимость акций.

Среди основных характеристик стратегии цифровизации IKEA можно выделить следующие:

- изменение форматов самих магазинов: создание мини-IKEA, для того чтобы протестировать продукты собственноручно, а потом принять решение дома. Появление таких магазинов в сочетании с цифровизацией - это ответ потенциальному снижению популярности больших магазинов IKEA, расположенных за городом;

- сохранение доступных цен на продукцию, несмотря на значительные инвестиции в цифровизацию, которые осуществляются за счет сокращения собственной маржи (это сделано для того, чтобы удержать клиентов, при этом предложив им новый уникальный опыт);

- создание 11500 новых рабочих мест при сокращении 7500 старых, которые связаны с дублированием функций. Такая статистика противоречит общепринятому мнению, что цифровизация однозначно ведет к сокращению рабочих мест;

- цифровизация как процессов, в том числе в рамках цепочки поставок, так и продуктов;

• цифровизация как часть культуры компании, которая интегрируется в общую предпринимательскую культуру компании, где каждый сотрудник считается предпринимателем.

Отдельные инициативы в области цифровизации, которые были внедрены или пла- нируются к внедрению в IKEА, представлены на рис. 10. Одним из инструментов стимулирования появления цифровых инноваций в компании Ingka Group, которой принадлежит IKEA, является приобретение инновационных компаний/стартапов. В феврале 2020 г. компания приобрела компанию Geomagical Labs, занимающуюся 3D-технологиями и использованием искусственного интеллекта в области визуализации ${ }^{11}$. Наработки данной компании планируется внедрить в деятельность компании, чтобы клиенты могли интерактивно делать дизайн своих домов. Еще одним более ранним приобретением IKEA является платформа TaskRabbit. Также с целью создания инноваций, в том числе цифровых, компания создала инновационный хаб и выставочное пространство Space10. Данный хаб объединяет новаторов из всех сфер. В результате некоторые будущие наработки данного хаба могут стать частью компании IKEA ${ }^{12}$.

Два рассмотренных примера подтверждают необходимость стратегии цифровизации для компании, а также ее успешность при комплексном подходе к ее разработке и внедрению.

Анализ открытых данных белорусских компаний позволяет сделать вывод, что в республике нет примеров разработки и внедрения стратегии цифровизации устоявшимися бизнесами. Активно в этой части работают только компании, которые сами изначально делали ставку на цифровые модели, например крупнейший онлайн-гипермаркет 21vek.by. У многих из них нет даже корпоративных стратегий. В дальнейшем белорусским компаниям всех отраслей важно рассмотреть возможность разработки стратегии цифровизации, которая будет увязана с корпоративной стратегией, с целью обеспечить свою конкурентоспособность на внутреннем и внешних рынках.

$$
* \quad * \quad *
$$

Таким образом, стратегия цифровизации бизнеса - это важный элемент развития бизнеса на данный момент, который позволяет

${ }^{11}$ URL: https://www.fastcompany.com/90485649/ikeasnew-digital-strategy-engages-users-where-they-are-at-home

${ }_{12}$ URL: https://www.forbes.com/sites/bernardmarr/2018/ 10/19/the-amazing-digital-transformation-of-ikea-virtual-realityapps-self-driving-cars/\#7434e4a776be 


\section{Стратегия цифровизации международных компаний}

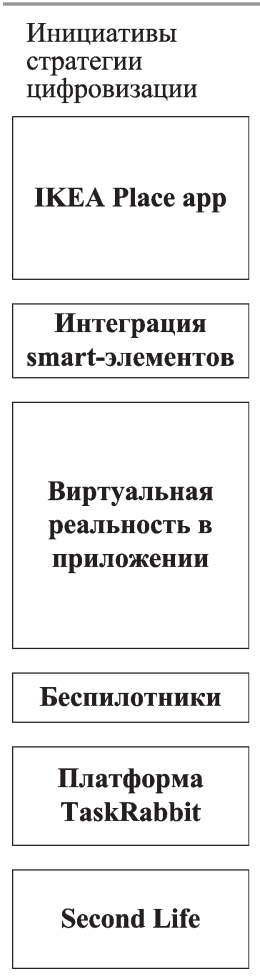

Описание

Приложение, основанное на использовании дополненной реальности (позволяет пользователям представить, как элементы интерьера от IKEA будут выглядеть конкретно в комнате покупателя)

Возможность получения информации об альтернативных цветах, материалах предметов интерьера при наведении на него смартфона в новых мини-магазинах IKEA в центре города

Интеграция smart-элементов в продукцию IKEA для создания покупателем «умного дома»

Возможность для покупателей загрузить фотографию своей комнаты на платформу IKEA, где фотография будет переведена в 3D-формат, после чего все существующие вещи будут убраны, а покупатель может разместить в 3D-комнате элементы интерьера IKEA

Возможность приобрести понравившиеся вещи в приложении

В дальнейшем, используя искусственный интеллект, возможность на данной платформе предложить клиенту варианты элементов интерьера, исходя из предпочтений покупателя

Использование беспилотников как направление, которое активно обсуждается на данный момент

Платформа, которая дает возможность покупателям связываться с теми, кто готов организовать доставку, сборку мебели IKEA

Проект, который позволяет покупателям продавать использованную мебель в магазин, после того как на нее поступает онлайн-запрос

Рис. 10. Инициативы стратегии цифровизации компании в IKEA

Источник. URL: https://www.fastcompany.com/90485649/ikeas-new-digital-strategy-engages-users-where-they-are-athome; URL: https://www.cnbc.com/2019/03/21/amazon-is-a-threat-but-ikeas-digital-chief-says-she-has-a-plan.html; URL: https://www.forbes.com/sites/bernardmarr/2018/10/19/the-amazing-digital-transformation-of-ikea-virtual-reality-apps-selfdriving-cars/\#7434e4a776be

быстро реагировать на предпочтения потребителей и изменения в конкурентной среде. Стратегия цифровизации дает компаниям возможность увеличить продажи, а также сократить издержки, повысив удовлетворенность покупателей и сотрудников. Наличие стратегии цифровизации бизнеса и ее суть во многом зависят от степени цифровой трансформации конкретной отрасли, а также от готовности и понимания руководства важности данной стратегии. Среди ключевых факторов успеха стратегии цифровизации можно выделить желание и активное вовлечение в цифровизацию бизнеса руководителя компании, нестандартный и креативный взгляд на развитие отрасли и компании, понимание рисков цифровизации и способов их минимизации, скорость и смелость в принятии решения, а также наличие профессиональной команды и технологической платформы в компании. Разработка стратегии цифровизации может включать несколько основных этапов: от постановки цели цифровизации до разработки конкретного плана действий и определения ответственных. Ос- новой стратегии цифровизации является система, позволяющая создавать цифровые инновации. Она включает как компетенции, так и конкретные инструменты стимулирования инноваций (например, бизнес-акселераторы, корпоративные венчурные фонды), а также источники финансирования. В качестве успешных примеров разработки и внедрения стратегии цифровизации белорусские компании могут использовать кейсы известных международных компаний.

\section{СПИСОК ЛИТЕРАТУРЫ (REFERENCES)}

Давыденко Е.Л., Ботеновская Е.С., Жуковская О.Ю., Столярова Е.В., Руденков В.М., Матюшевский Я.В. 2019. Страны с малой экономикой в условиях интеллектуализации, дигитализащии и экологизащии. Минск: ИВЦ Минфина. 346 c. [Davydenko E.L., Botenovskaya E.S., Zhukovskaya O.Yu., Staliarova K.V., Rudenkov V.M., Matyushevsky Ya.V. 2019. Small economies in the context of intellectualization, digitalization and greening. Minsk: IVTs Minfina. 346 p. (In Russ.)] 
Ковалев М.М., Головенчик Г.Г. 2018. Цифровая экономика - шанс для Беларуси. Минск: Издательский центр БГУ. 327 с. [Kovalev M.M., Golovenchik G.G. 2018. Digital economy - a chance for Belarus. Minsk: Izdatel'skiy tsentr BGU. 327 p. (In Russ.)]

Bharadwaj A., El Sawy O.A., Pavlou P.A, Venkatraman N. 2013. Digital business strategy: toward a next generation of insights. MIS Quarterly. Vol. 37. No 2. PP. 471-482.

Chan Y. E., Reich B. H. 2007. IT alignment: what have we learned? Journal of Information Technology. Vol. 22. PP. 297-315.

Wald D., de Laubier R., Charanya T. 2019. The five rules of digital strategy. BCG. URL: https:/ /www.bcg.com/publications/2019/five-rules-digitalstrategy.aspx

In citation: Belorusskiy Economicheskiy zhurnal. 2020. No 3. PP. 132-148. Belarusian Economic Journal. 2020. No 3. PP. 132-148.

\section{DIGITAL STRATEGY OF INTERNATIONAL COMPANIES}

\section{Katsiaryna Staliarova ${ }^{1}$}

Authors affiliation: ${ }^{1}$ Belarusian State University (Minsk, Belarus).

Corresponding author: Katsiaryna Staliarova (e.staliarova@gmail.com),

ABSTRACT. The article reveals the concept of digital strategy and gives its distinctions from IT-strategy. It also covers stages of digital transformation in the industry. Key factors that curb digitization as well as critical success factors for digital strategy of international companies are identified. We propose an approach for digital strategy development and a system to stimulate digital innovations in the company. Thus experiences of Domino's and IKEA in building and implementing of digital strategy were reviewed;conclusions on the need of such a strategy for belarusian companies are made.

KEYWORDS: international business, digital strategy, digitalization, strategy, international companies.

JEL-code: F18, F23.

DOI: $10.46782 / 1818-4510-2020-3-132-148$

Received 4.05.2020 